\title{
Application of the island pedicle latissimus dorsi flap for soft tissue coverage of the elbow
}

\author{
Edward J Harvey MDCM ${ }^{1}$, Reynaldo Aponte PA-C ${ }^{2}$, L Scott Levin MD ${ }^{2}$ \\ ${ }^{l}$ Department of Orthopaedics, McGill University Health Center, Montreal General Hospital, Montreal, \\ Quebec; ${ }^{2}$ Departments of Orthopaedic and Plastic/Reconstructive Surgery, Duke University Medical \\ Center, Durham, North Carolina, United States
}

\begin{abstract}
EJ Harvey, R Aponte, LS Levin. Application of the island pedicle latissimus dorsi flap for soft tissue coverage of the elbow. Can J Plast Surg 1999:7(1):23-26.

Soft tissue coverage of large defects at the level of the elbow is a difficult undertaking. Superficial neurovascular elements and a thin subcutaneous covering of the osseous structures do not allow a great variety of coverage options. A systematic reconstruction scheme for tissue defects in the upper extremity, as there is for defects in the lower extremity, does not exist. Coverage of the elbow has traditionally been accomplished with local transpositional flaps or free tissue transfer. At the elbow, local flaps are more likely to be involved in the original disease process. Long operative procedures and dependence on local blood supply, difficulties inherent in free tissue transfer, can be avoided with the use of the pedicled latissimus dorsi flap. This easily tailored flap allows the coverage of large defects at the elbow level. A case series of six patients and a description of the operative technique used for a pedicled island flap of the latissimus dorsi are reported.
\end{abstract}

Key Words: Elbow, Flap, Latissimus dorsi, Tissue transfer, Trauma

\section{Application d'un lambeau pédiculaire insulaire du latissimus dorsi pour le recouvrement des tissus mous au niveau du coude}

\begin{abstract}
RÉSUMÉ : Le recouvrement des tissus mous en présence de lésions de grandes surfaces au niveau du coude est une entreprise délicate. Les éléments neurovasculaires superficiels et une mince couverture sous-cutanée des structures osseuses n'offrent pas beaucoup de possibilités. La reconstruction systématique des lésions tissulaires, comme c'est le cas pour les anomalies des membres inférieurs, est impraticable au niveaux des membres supérieurs. Le recouvrement du coude s'est de tout temps effectué au moyen de lambeaux de transposition locaux ou de transfert de tissu libre. Au niveau du coude, les lambeaux locaux sont plus susceptibles d'être associés au processus pathologique original. Des interventions chirurgicales longues, la dépendance à l'endroit de l'approvisionnement sanguin local et les difficultés inhérentes au transfert de tissu libre peuvent être évités si l'on a recours au lambeau pédiculé du latissimus dorsi. Ce lambeau, facile à ajuster, permet de recouvrir les lésions volumineuses du coude. On présente ici une série de six cas et la description de la technique opératoire utilisée pour un lambeau insulaire pédiculé du latissimus dorsi.
\end{abstract}

Soft tissue coverage for large defects at the elbow level is Not an easy task. Typically, these defects are associated with trauma, tumour or infection. Infectious problems requiring soft tissue reconstruction include olecrenon bursitis, pyarthrosis and osteomyelitis. The relatively superficial course of major neurovascular structures and the proximity of the elbow joint to the skin at this level mandate reconstruc-

Correspondence: Dr Edward J Harvey, McGill University Health Center, Department of Orthopaedics, Suite D10-1560, 1650 Cedar Avenue, Montreal, Quebec H3G 1A4. Telephone 514-937-6011 ext. 2734, fax 514-934-8394 tion of the soft tissue if these disease entities result in a large soft tissue defect. The impact of treatment on the future function of the upper extremity and the expected outcome for each patient must be taken into consideration. Primary closure, or skin grafting and immobilization, can result in less than desirable results with resultant contractures (1-5). Even if possible, primary closure may not be sufficient in an open wound over exposed hardware or in the treatment of infection.

Any large defect or complicated wound about the elbow has traditionally been treated with flap coverage - either local or transported free tissue (5). Local flaps are often not 


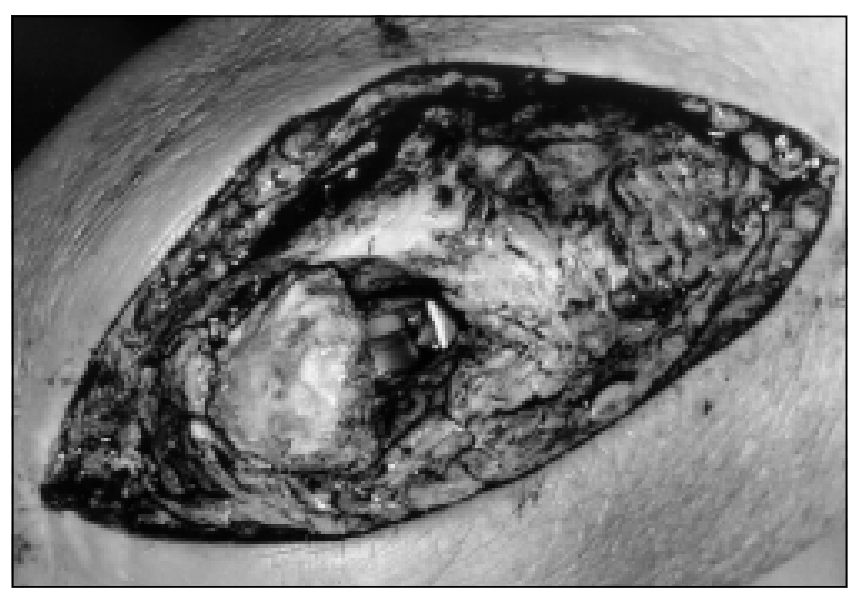

Figure 1) Acutely infected total elbow arthroplasty with area of skin necrosis after debridement

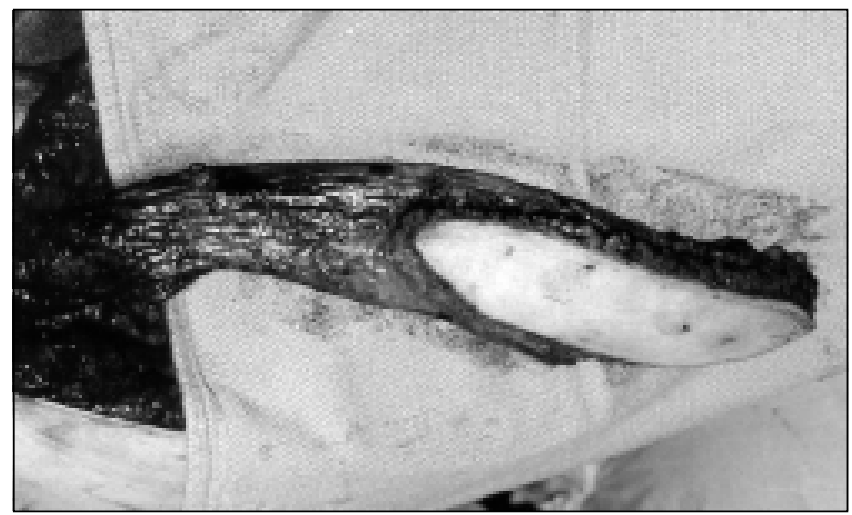

Figure 2) Pedicled latissimus dorsi muscle flap

ideal in the upper extremity at the elbow; they often can only cover restricted areas. The brachioradialis flap is an example of a local transfer flap that can only cover a minimal area. Pedicled flaps, such as the radial forearm flap, have inherent difficulties that include further iatrogenic trauma to a limb already at risk. Local flaps are prone to involvement with the original local disease process of sepsis, tumour or trauma, and may not be ideal for coverage in many patients (4-6).

Free tissue transfer offers the surgeon the greatest number of options $(2,5)$; however, it relies on the vascular supply at the elbow level, which in some processes is compromised by the disease process. The upper extremity often needs to be immobilized, which can jeopardize the overall results of the procedure. Distal pedicle flaps from the thorax or groin can overcome the problem of local blood supply and decrease the time of surgery compared with free tissue transfer. However, the limb still needs to be immobilized, often in an inconvenient position, and the patient requires further surgery. The pedicle of the graft needs to be taken down from the donor site at a later date $(5,7)$. Some pedicles need to be staged and taken down with more than one additional procedure. This increases hospital stay and patient costs, and inhibits patient rehabilitation. The use of the island pedicle latissimus dorsi

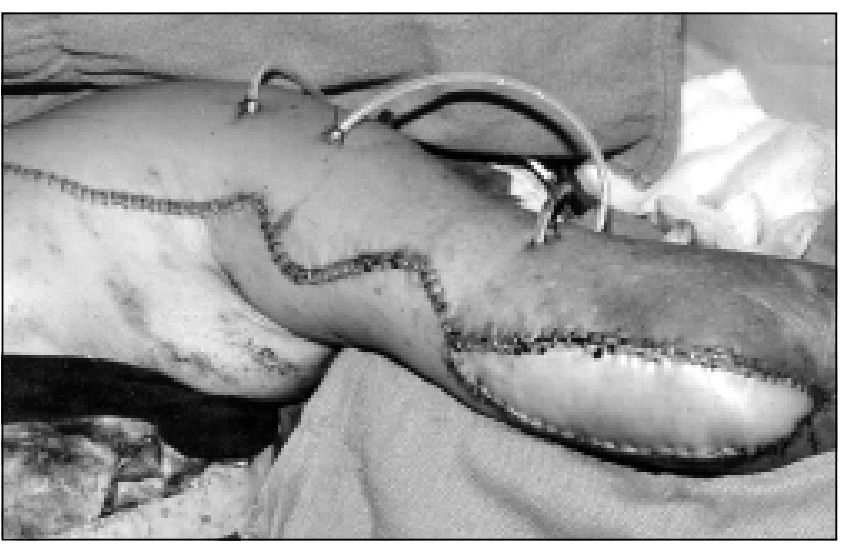

Figure 3) Insetting of the flap performed under a long Z-plasty from the vessel origin

flap for soft tissue coverage of the elbow avoids many of these difficulties. The latissimus dorsi muscle offers a long, large calibre vascular supply based in an area remote from the disease process. This flap can be fashioned with a large cutaneous element. The arm does not have to be protected with prolonged immobilization, so that the complication of postoperative contracture can be diminished. The large bulk of the latissimus dorsi muscle, which can be tailored to the size of the defect, makes it ideal for coverage of hardware, treatment of infection at the elbow, tumour reconstruction or placement in previously radiated beds (Table 1).

\section{MATERIALS AND METHODS}

The latissimus dorsi island flap has been described previously $(1,8,9)$, but is usually reserved for soft tissue coverage about the shoulder and upper arm. Traditionally, about the elbow, this flap has been used as a free tissue transfer. With appropriate dissection, it can be transposed on its pedicle for coverage of the elbow and proximal forearm (1,8-10). The flap is designed according to the defect that needs to be filled (Figure 1). The entire muscle is not always needed for elbow reconstruction.

After primary debridement of the elbow region, a template is designed based on the missing cutaneous element. If the entire muscle is not to be used for the graft, the flap is tailored to be based on the anterior thoracodorsal artery, leaving the muscle that is dependent on the lateral thoracodorsal artery intact. If more muscle is needed for coverage, the serratus can be harvested in the same dissection. The template is placed on the distal portion of the latissimus muscle and used to outline the area of skin needed. Only the anterior portion of the muscle with the distally based skin is transported. The cutaneous portion should be on the anterior muscle, where perforators from the anterior thoracodorsal artery will perfuse it, but should not be placed so far distally as to become a dependent random flap in which necrosis of part of the distal skin paddle will occur. The latissimus flap is then raised in the normal fashion (Figure 2). 
TABLE 1

Cases with pedicled latissimus transfer

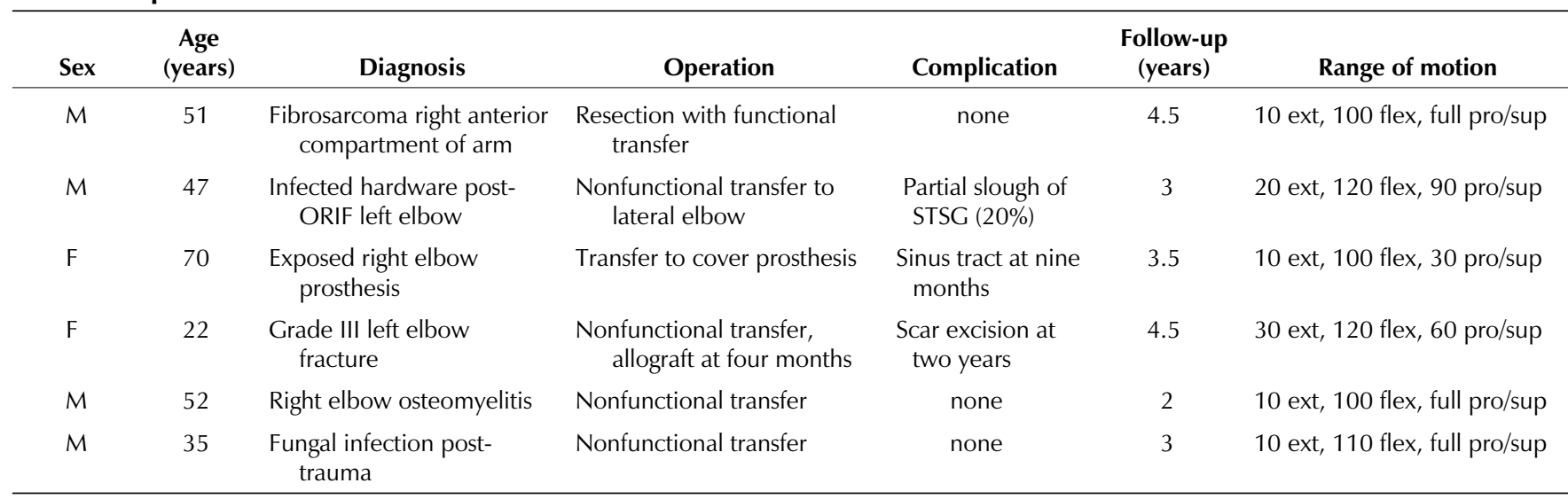

ext Extension; F Female; flex Flexion; M Male; ORIF Open reduction with internal fixation; pro Pronation; STSG Split-thickness skin graft; sup Supination

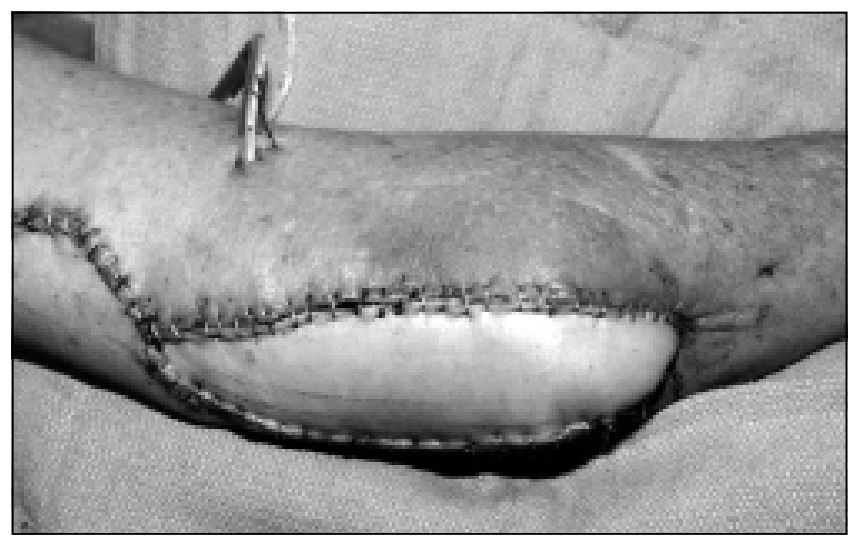

Figure 4) Insetting of the flap $3 \mathrm{~cm}$ beyond the olecrenon

The humeral attachment can be left intact if the muscle is to be used as a functional muscle flap for replacement of elbow extension or flexion. In this case, the thoracodorsal nerve is retained with the flap. If the flap is designed only for coverage, the humeral attachment is dissected free and the nerve is either cut or left behind to innervate the posterior latissimus muscle that remains. The dissection of the vascular pedicle should be carried to the circumflex scapular vessels to ensure the maximal flap length. Adequate observation of this juncture is important during the rotation of the flap. A subcutaneous tunnel is never used to pass the flap into the arm. Using a tunnel can cause problems with flap engorgement, which are difficult to predict and treat. Instead, lengthening Z-plasties are made along the course of the flap (Figure 3 ). The muscle may be passed anteriorly before being inset into the arm. Theoretically, a slightly greater reach of the distal flap can be obtained by passing the muscle anteriorly. In practice, this flap is useful to the forearm muscle bellies and can almost always be inset at least $3 \mathrm{~cm}$ past the olecrenon (Figure 4). Insetting of the flap occurs with the arm in extension and the shoulder in abduction, which is the position of postoperative immobilization. The arm is splinted for several days and then gradually taken into flexion. The shoulder is taken through daily range of motion or exercises to avoid capsular contracture. Mobilization of the elbow begins on the seventh postoperative day.

\section{RESULTS}

The patients who had pedicled latissimus dorsi transfers are listed in Table 1. Six latissimus transfers using the above technique were performed for a variety of disorders. The average follow up of these patients was 3.4 years (range two to 4.5 years). There were three complications, all of which were treated surgically. One patient had a partial slough of the split thickness skin graft that was successfully re-grafted. One patient developed a sinus tract under her flap at nine months postoperation. It was excised, and she is now 21 months post-sinus excision with no difficulties. Another patient had revision surgery for scar excision and flap debulking. There were no cases of flap failure.

\section{DISCUSSION}

Large soft tissue defects around the elbow are difficult to manage. Traditional methods of closure may not be an option in a large defect. The need for urgent closure over vital neurovascular structures is apparent. The island pedicle latissimus dorsi can be used to afford coverage as far as the forearm, and is the first choice for soft tissue coverage that requires restoring function to either the anterior or posterior arm. As has been illustrated, this is an easy procedure without the attendant difficulties of free tissue transfer to an area that is often involved with the original disease process. Technical points that are important for the optimization of this flap are the use of Z-plasties instead of a tunnel, positioning of the arm with elbow extension and shoulder abduction, and insetting of the flap with the arm in extension and the shoulder in abduction. With further development, endoscopic harvesting of the latissimus dorsi muscle could decrease patient recovery time. This flap should be considered a prime option for soft tissue coverage of the elbow. 


\section{REFERENCES}

1. Chang LD, Goldberg NH, Chang B, Spence R. Elbow defect coverage with a one-staged, tunneled latissimus dorsi transposition flap. Ann Plast Surg 1994;32:496-502.

2. Kleinman WB, Putnam MD. Microvascular free-tissue transfers to the hand and upper extremity. Hand Clin 1989;5:423-44.

3. Lai CS, Lin SD, Yang CC, Chou CK. The adipofascial turnover flap for elbow coverage. Ann Plast Surg 1992;28:190-4.

4. Orgill DP, Pribaz JJ, Morris DJ. Local fasciocutaneous flaps for olecranon coverage. Ann Plast Surg 1994;32:27-31.

5. Russell RC, Zamboni WA. Coverage of the elbow and forearm. Orthop Clin North Am 1993;24:425-34.
6. Him FP, Casanova R, Vasconez LO. Myocutaneous and fasciocutaneous flaps in the upper limb. Hand Clin 1985;1:759-68.

7. Hallock GG. A schema for local flap selection in the upper extremity: a hypothesis. Ann Plast Surg 1990;25:479-83.

8. Moneim MS, Omer GE. Latissimus dorsi muscle transfer for restoration of elbow flexion after brachial plexus disruption. J Hand Surg [AM] 1986;11:135-9.

9. MacKinnon SE, Weiland AJ, Godina M. Immediate forearm reconstruction with a functional latissimus dorsi island pedicle myocutaneous flap. Plast Reconstr Surg 1983;71:706-10.

10. Landra AP. The latissimus dorsi musculocutaneous flap used to resurface a defect on the upper arm and restore extension to the elbow. Br J Plast Surg 1979;32:275-7. 